This item was submitted to Loughborough's Research Repository by the author.

Items in Figshare are protected by copyright, with all rights reserved, unless otherwise indicated.

\title{
Green synthesis of silver and copper nanoparticles using ascorbic acid and chitosan for antimicrobial applications
}

PLEASE CITE THE PUBLISHED VERSION

http://dx.doi.org/10.1016/j.carbpol.2014.05.081

\section{PUBLISHER}

(C) Elsevier Ltd.

\section{VERSION}

AM (Accepted Manuscript)

\section{PUBLISHER STATEMENT}

This work is made available according to the conditions of the Creative Commons Attribution-NonCommercialNoDerivatives 4.0 International (CC BY-NC-ND 4.0) licence. Full details of this licence are available at: https://creativecommons.org/licenses/by-nc-nd/4.0/

\section{LICENCE}

CC BY-NC-ND 4.0

\section{REPOSITORY RECORD}

Zain, N.M., A.G.F. Stapley, and Gilbert Shama. 2014. "Green Synthesis of Silver and Copper Nanoparticles Using Ascorbic Acid and Chitosan for Antimicrobial Applications”. figshare. https://hdl.handle.net/2134/16144. 
1 Green synthesis of silver and copper nanoparticles using ascorbic acid and

N. Mat Zain ${ }^{\mathrm{a}, \mathrm{b}}$, A. G. F. Stapley ${ }^{\mathrm{a}^{\star}}$, G. Shama $^{\mathrm{a}}$

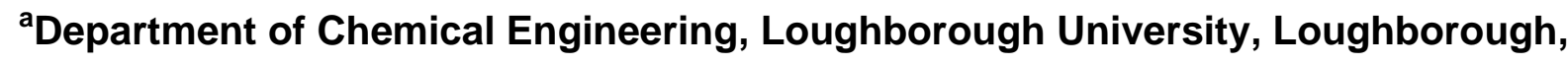
Leicestershire, LE11 3TU, United Kingdom.

\section{${ }^{b}$ Department of Chemical Engineering, Universiti Malaysia Pahang, Highway Tun} Razak, 26300 Kuantan, Pahang, Malaysia.

*Corresponding author: Tel: +44 (0)1509 222525, Fax: +44(0)1509 223923

Email addresses: shikin@ump.edu.my (N. Mat Zain), A.G.F.Stapley@Lboro.ac.uk, G.Shama@Lboro.ac.uk

\section{Abstract}

Silver and copper nanoparticles were produced by chemical reduction of their respective nitrates by ascorbic acid in the presence of chitosan using microwave heating. Particle size was shown to increase by increasing the concentration of nitrate and reducing the chitosan concentration. Surface zeta potentials were positive for all nanoparticles produced and these varied from 27.8 to $33.8 \mathrm{mV}$. Antibacterial activities of $\mathrm{Ag}, \mathrm{Cu}$, mixtures of $\mathrm{Ag}$ and $\mathrm{Cu}$, and $\mathrm{Ag} / \mathrm{Cu}$ bimetallic nanoparticles were tested using Bacillus subtilis and Escherichia coli. Of the two, B. subtilis proved more susceptible under all conditions investigated. Silver nanoparticles displayed higher activity than copper nanoparticles and mixtures of nanoparticles of the same mean particle size. However when compared on an equal concentration basis $\mathrm{Cu}$ nanoparticles proved more lethal to the bacteria due to a higher surface area. The highest antibacterial activity was obtained with bimetallic $\mathrm{Ag} / \mathrm{Cu}$ nanoparticles with minimum inhibitory concentrations (MIC) of 0.054 and $0.076 \mathrm{mg} / \mathrm{L}$ against $B$. subtilis and $E$. coli respectively. 
Keywords: Bimetallic nanoparticles; Minimum inhibitory concentration; Minimum bactericidal concentration; Bacillus subtilis; Escherichia. coli

\section{Introduction}

Interest in metal nanoparticles as antimicrobial agents is now over a decade old (Dai \& Bruening, 2002). The large number of particles that can be made and the high surface area to volume ratio allows nanoparticles to be effective in very small amounts (Sundaresan, Sivakumar, Vigneswaran, \& Ramachandran, 2012). Ag nanoparticles have been extensively used for biomedical applications (Marambio-Jones \& Hoek, 2010). $\mathrm{Cu}$ is relatively non-toxic to mammals, (Flemming \& Trevors, 1989) but is toxic towards many micro-organisms and this offers new prospects for antimicrobial treatments (Hsiao, Chen, Shieh, \& Yeh, 2006).

A number of methods for producing $\mathrm{Ag}$ and $\mathrm{Cu}$ nanoparticles have been developed using both physical and chemical approaches. The most frequently applied method for the preparation of Ag nanoparticles is the chemical reduction of silver salt solutions in water or an organic solvent to produce a colloidal suspension. The most common approach for synthesizing Cu nanoparticles is by creating microemulsions (Solanki, Sengupta, \& Murthy, 2010). However, the microemulsion technique requires large amounts of surfactants and organic solvents which increases the cost of production (El-Nour, Eftaiha, Al-Warthan, \& Ammar, 2010). Physical methods using laser ablation, radiolysis or aerosol techniques, although effective, require expensive instruments and consume large amounts of energy (Thakkar, Mhatre, \& Parikh, 2010). These methods typically makes use of agents which are both toxic and environmentally polluting (Lim \& Hudson, 2004).

Methods based on chemical reduction offer the best chance of being both low cost and environmentally friendly. Ag nanoparticles have been synthesized using water as solvent and starch as a capping agent and these were shown to have advantages over conventional methods involving chemical agents that are associated with 
environmental toxicity (Sharma, Yngard, \& Lin, 2009). The synthesis of Ag nanoparticles using chitosan as both a reducing and a capping agent has also been developed (Sanpui, Murugadoss, Prasad, Ghosh, \& Chattopadhyay, 2008). In addition, Cu nanoparticles have been made using alginate as a stabilizing agent (Díaz-Visurraga et al., 2012).

More recently, nanoparticles involving alloys of two metals have been produced. Valodkar, Modi, Pal, \& Thakore (2011) synthesized bimetallic Ag and Cu nanoparticles using starch and Said-Galiev et al. (2011) have synthesized Ag and Cu nanoparticles using chitosan. These had been treated with supercritical carbon dioxide followed by reduction of $\mathrm{Ag}$ and $\mathrm{Cu}$ organometallic complexes with hydrogen to form metal-chitosan nanoparticles. Bimetallic $\mathrm{Ag}$ and $\mathrm{Cu}$ nanoalloys have also been generated from silver nitrate and copper acetate solution with hydrazine hydrate as a reducing agent (Taner, Sayar, Yulug, \& Suzer, 2011).

This work is an attempt to further develop the green synthesis of $\mathrm{Ag}$ and $\mathrm{Cu}$ nanoparticles, mixtures of $\mathrm{Ag}$ and $\mathrm{Cu}$ nanoparticles (denoted as " $\mathrm{Ag}+\mathrm{Cu}$ ") and alloy nanoparticles of $\mathrm{Ag}$ and $\mathrm{Cu}$ (denoted as " $\mathrm{Ag} / \mathrm{Cu}$ ") with chitosan as a stabilizing agent and using microwave heating. The attraction of using chitosan for this function compared to starch is that it possesses antimicrobial properties (No, Park, Lee, \& Meyers, 2002), and can be readily solubilised using organic acids (Muzzarelli et al., 1984; Muzzarelli, 1985). Chitosan can form various chemical bonds with metals components thus enhancing the stability of the nanoparticles (Muzzarelli, 2011). It has low toxicity and it is therefore safe for human applications (Muzzarelli, 2010), although it is acknowledged that the metallic nanoparticles produced may well have some environmental toxicity (Li et al., 2010).

In this study nanoparticles were synthesized at different concentrations of chitosan. The synthesized nanoparticles were characterized by spectrophotometry and by the use of a zetasizer. Their antibacterial properties were tested using Bacillus subtilis and Escherichia coli. 


\section{Materials and methods}

\section{$2.1 \quad$ Reagents}

Copper (II) nitrate $\left(\mathrm{Cu}\left(\mathrm{NO}_{3}\right)_{2} . \mathrm{xH}_{2} \mathrm{O}\right)$ (Sigma Aldrich Chemie $\mathrm{GmbH}$, Steinheim, Germany), silver nitrate $\left(\mathrm{AgNO}_{3}\right)(\mathrm{BDH}$ Ltd, Poole, United Kingdom), L-ascorbic acid (Sigma Aldrich, Poole, United Kingdom), acetic acid (Fisher Scientific, Loughborough, United Kingdom) and chitosan (Sigma Aldrich, Poole, United Kingdom) were used for synthesis of the nanoparticles. The molecular weight of the chitosan was in the range 50000 - $190000 \mathrm{Da}$ and was 75-85\% deacetylated. All reagents were used without further purification.

\subsection{Preparation of chemical solutions}

The following solutions were all prepared using distilled water: silver nitrate $(10$, 30 and $50 \mathrm{mM})$, copper nitrate $(10,30$ and $50 \mathrm{mM})$, ascorbic acid $(10 \% \mathrm{w} / \mathrm{v})$. Chitosan solutions (1, 2 and $3 \% \mathrm{w} / \mathrm{v})$ were prepared by dissolving chitosan in $1 \%(\mathrm{v} / \mathrm{v})$ acetic acid solution. These were then left for 3 days to allow the chitosan to completely dissolve (Wei, Sun, Qian, Ye, \& Ma, 2009).

\subsection{Preparation of nanoparticles}

\subsubsection{Ag and Cu nanoparticles}

For the preparation of $\mathrm{Ag}$ or Cu nanoparticles solution, $40 \mathrm{~mL}$ of silver nitrate or copper nitrate solution $(10,30$ or $50 \mathrm{mM}$ ) was mixed with $40 \mathrm{~mL}$ of chitosan solution (1, 2 or $3 \% \mathrm{w} / \mathrm{v}$ ) and $4 \mathrm{~mL}$ of $10 \%(\mathrm{w} / \mathrm{v})$ ascorbic acid solution. The reduction reaction was carried out by heating in a microwave oven (EM-SI067 UK, Sanyo, China) at full power of 800 W for 4 minutes (Valodkar, Modi, Pal, \& Thakore, 2011).

\subsubsection{Bimetallic Ag/Cu nanoparticles}

For the preparation of bimetallic nanoparticles hereinafter referred to as " $\mathrm{Ag} / \mathrm{Cu}$ " nanoparticles, $20 \mathrm{~mL}$ of silver nitrate solution and $20 \mathrm{~mL}$ of copper nitrate solution were mixed with $40 \mathrm{~mL}$ of $3 \%(\mathrm{w} / \mathrm{v})$ chitosan and $4 \mathrm{~mL}$ of $10 \%(\mathrm{w} / \mathrm{v})$ ascorbic acid solution. 
The reaction was then carried out under microwave at full power of $800 \mathrm{~W}$ for 4 minutes (Valodkar et al., 2011).

\subsubsection{Mixtures of $\mathrm{Ag}$ and $\mathrm{Cu}$ nanoparticles}

For the preparation of simple mixtures of $\mathrm{Ag}$ and $\mathrm{Cu}$ nanoparticles, subsequently referred to as "Ag + Cu" nanoparticles, $40 \mathrm{~mL}$ of $\mathrm{Ag}$ nanoparticles and $40 \mathrm{~mL}$ of $\mathrm{Cu}$ nanoparticles were separately synthesized in $3 \%(\mathrm{w} / \mathrm{v})$ of chitosan as described in section 2.3.1 and then mixed together (Valodkar et al., 2011).

\subsection{Characterization of nanoparticles}

\subsubsection{Spectrophotometry}

UV-vis absorption spectra of $\mathrm{Ag}, \mathrm{Cu}, \mathrm{Ag} / \mathrm{Cu}$ and $\mathrm{Ag}+\mathrm{Cu}$ nanoparticles solutions were taken over the wavelength range 200 to $800 \mathrm{~nm}$ using UV-vis spectrophotometer model UV mini-1240 (Shimadzu Corporation, Kyoto, Japan).

\subsubsection{Particle size and zeta potential analysis}

Particle sizes of $\mathrm{Ag}, \mathrm{Cu}, \mathrm{Ag} / \mathrm{Cu}$ and $\mathrm{Ag}+\mathrm{Cu}$ nanoparticle solutions were measured using a Zetasizer instrument (Model ZEM5002, Malvern Instruments Ltd, Malvern, UK) using UV Grade cuvettes after treatment in an ultrasonic water bath (Model FB11012, Fisherbrand, Loughborough, UK) for 30 min to break up any aggregates present (Ribeiro, Hussain, \& Florence, 2005). The zeta potentials of each type of nanoparticle were measured using a Zetasizer model 3000HS (Malvern Instrument Ltd, Malvern, UK). All measurements were performed in triplicate.

\section{$2.5 \quad$ Microbiological methods}

\subsubsection{Bacteria}

The Gram-positive bacterium, Bacillus subtilis ATCC 6633 was obtained from the National Collections of Industrial, Food and Marine Bacteria (NCIMB), Aberdeen, Scotland and the Gram-negative bacterium, E. coli K12 was kindly donated by Dr Jon Hobman of Nottingham University, Nottingham, United Kingdom. 


\subsubsection{Cultivation of bacteria}

Bacteria were taken from frozen $\left(-80^{\circ} \mathrm{C}\right)$ stock and streaked onto Tryptone Soy Agar (TSA) and incubated overnight at $37^{\circ} \mathrm{C}$. A single colony was then used to inoculate $100 \mathrm{~mL}$ of Tryptone Soy Broth (TSB) in a $500 \mathrm{~mL}$ Erlenmeyer flask which was then placed in a shaking incubator at $37^{\circ} \mathrm{C}$ at a speed of $140 \mathrm{rpm}$ for 12 hours. Following this, $100 \mu \mathrm{L}$ of this culture was used to inoculate $100 \mathrm{~mL}$ of fresh TSB incubated at the same conditions as described above until the mid-logarithmic phase had been attained. The culture at this point was suitably diluted in phosphate buffered saline (PBS) to yield a suspension containing $10^{8}$ colony forming units (CFU) per $\mathrm{mL}$. Identical procedures were followed for both $B$. subtilis and $E$. coli.

\subsubsection{Determination of the minimum inhibitory concentration (MIC) and minimum} bactericidal concentration (MBC)

A range of dilutions of nanoparticles in sterile distilled water were prepared and 4 $\mathrm{mL}$ of the dilution was added to $20 \mathrm{~mL}$ of TSB medium with $20 \mathrm{~mL}$ of bacteria of $10^{8}$ $\mathrm{CFU} / \mathrm{mL}$ and incubated in an incubator shaker (model CERTOMAT ${ }^{\circledR}$ BS-1, Sartorius, Göttingen, Germany) at $37^{\circ} \mathrm{C}$ overnight (Cao et al., 2010). The MIC was determined by visual observation and confirmed by turbidity measurement using a UV-vis spectrophotometer (Jenway 6300, Bibby Scientific Ltd, Essex, UK) at $600 \mathrm{~nm}$ before and after incubation. Diluted aliquots $(100 \mu \mathrm{L})$ of those samples in which growth of the bacteria was not observed were spread plated using TSB to determine the minimum bactericidal concentration (MBC). The samples were incubated at $37^{\circ} \mathrm{C}$ overnight and the colonies formed were observed. The MBC was determined as the lowest concentration that inhibited the visible growth of the bacteria tested (Wei et al., 2009).

\subsection{Statistical analysis}

The data from triplicate experiments are presented as the mean and the standard error of the mean. The statistical analysis of the results was performed using one-way ANOVA with Bonferroni multiple comparison post hoc test. All statistical analyses were performed using IBM SPSS Statistics 21.0 (SPSS UK Ltd., Surrey, United Kingdom). 


\section{Results and discussion}

\subsection{Physical characteristics}

Images of the nanoparticle suspensions prepared according to the methods described above are presented in Fig. 1. The formation of colloidal suspensions of nanoparticles was evident from visual inspection of the reagent mixtures following microwave heating. Ag nanoparticles (Fig. 1a) were of a light yellow colour which became stronger as the chitosan concentration was increased. The formation of metal nanoparticles was confirmed by UV-vis spectrophotometry. Fig. 2a shows an absorbance spectrum with a peak at approximately $420 \mathrm{~nm}$, indicating the formation of Ag nanoparticles (Ahmad et al., 2003). Ag nanoparticles have previously reported to be of yellowish colour in aqueous solution (Perera et al., 2013). The colour and absorbance spectra at $420 \mathrm{~nm}$ is due to the excitation of surface plasmon vibrations of Ag atoms (Twu, Chen, \& Shih, 2008). Increasing the chitosan concentration was found to result in a slight downward shift in the peak absorbance coupled with an overall increase in absorbance. These results are consistent with those obtained by Huang, Yuan, \& Yang (2004) who synthesized Ag nanoparticles in chitosan by reduction with sodium borohydride.

The Cu nanoparticles (Fig. 1b), varied in colour from light pink to deep red as the concentration of chitosan was increased. The UV spectrum (Fig. 2b) showed a peak at $550 \mathrm{~nm}$, which confirms the presence of Cu nanoparticles. These have been reported to be in the range of 500 to $600 \mathrm{~nm}$ (Mallick, Witcomb, \& Scurrell, 2006). Similarly, it has been reported that the color of the freshly synthesized $\mathrm{Cu}$ nanoparticle stabilized using a water soluble aminoclay matrix suspension was red which is characteristic of $\mathrm{Cu}$ nanoparticles (Datta, Kulkarni, \& Eswaramoorthy, 2010).

Fig. 1c shows that mixtures of $\mathrm{Ag}$ and $\mathrm{Cu}$ nanoparticles are orange in color (as would be expected from a blend) but alloyed nanoparticles of $\mathrm{Ag}$ and $\mathrm{Cu}$ were dark brown. Taner et al. (2011) formed bimetallic Ag/Cu nanoparticles by bringing about the 
reduction of metal salts in aqueous solution with hydrazine hydrate and also reported that the colour of the suspension was dark brown. UV-vis spectra of $\mathrm{Ag}+\mathrm{Cu}$ and $\mathrm{Ag} / \mathrm{Cu}$ nanoparticles are presented in Fig. 2c. The $\mathrm{Ag}+\mathrm{Cu}$ spectra show two distinct peaks at 420 and $550 \mathrm{~nm}$, indicating a physical mixture of $\mathrm{Ag}$ and $\mathrm{Cu}$ nanoparticles. The $\mathrm{Ag} / \mathrm{Cu}$ nanoparticles, on the other hand, showed a single absorbance peak at an intermediate ratio confirming that a bimetallic alloy had been formed (Valodkar et al., 2011).

In this study, chitosan was solubilized using dilute acetic acid solution. The chitosan reacts with $\mathrm{H}^{+}$from the acid solution to produce protonized chitosan with $-\mathrm{NH}_{3}{ }^{+}$ functional groups. The introduction of these functional groups into the chitosan backbone improves its solubility in water. When silver and copper nitrate were added to the chitosan solution, $\mathrm{Ag}^{+}$and $\mathrm{Cu}^{2+}$ ions would attach to chitosan macromolecules by electrostatic interactions, because the electron-rich oxygen atoms of polar hydroxyl and ether groups of chitosan are likely to interact with electropositive metal cations. A reducing agent is required to provide the free electrons needed to reduce ions and to form nanoparticles (Tolaymat et al., 2010). In this study, ascorbic acid was used as the reducing agent. $\mathrm{Ag}$ and $\mathrm{Cu}$ nanoparticles thus were formed by the reduction of $\mathrm{Ag}^{+}$and $\mathrm{Cu}^{2+}$ ions respectively, with an excess of ascorbic acid (for $100 \%$ conversion). The $\mathrm{Ag}$ and $\mathrm{Cu}$ nanoparticles are stabilized by protonized chitosan to prevent aggregation and to control the size of final nanoparticles produced. The same mechanism applies for the synthesis of $\mathrm{Ag} / \mathrm{Cu}$ nanoparticles.

\subsection{Mean particle size}

The changes in UV-vis absorbance referred to above indicate that the size of nanoparticles formed altered with the concentration of chitosan, which operates as a controller of nucleation as well as a stabilizer (Huang et al., 2004). Fig. 3 shows the mean particle size of $\mathrm{Ag}$ and $\mathrm{Cu}$ nanoparticles synthesized using $10 \mathrm{mM}$ salt solution at different concentrations of chitosan. It was observed that the mean particle sizes of both $\mathrm{Ag}$ and $\mathrm{Cu}$ nanoparticles decreased with increasing chitosan concentration and that for the same chitosan concentration Ag nanoparticles were slightly larger than $\mathrm{Cu}$ nanoparticles as presented in Fig. 3. This decrease is due to a protective action by 
chitosan whereby chitosan may prevent the growth of the nanoparticles by adsorbing onto their surfaces (Esumi, Takei, \& Yoshimura, 2003).

The effects of silver and copper nitrate concentration on the mean particle size of the nanoparticles are presented in Fig. 4. As the concentration of silver and copper nitrate increased from 10 to $50 \mathrm{mM}$, the size of nanoparticles increased almost proportionately. At the same concentration of chitosan, with increased concentration of metal salts, less protonized chitosan absorbed onto the pre-formed nanoparticles, and therefore larger nanoparticles were formed (Leung, Wong, \& Xie, 2010). Statistical analysis showed that the mean particle sizes of the nanoparticles are significantly different and influenced by the concentrations of chitosan and metal salts. Therefore, the size of the nanoparticles may be controlled either by adjusting the concentration of metal ions or the concentration of chitosan during the synthesis process.

\subsection{Zeta potential}

The zeta potential is a crucial parameter for determining the stability of nanoparticle suspensions. For a physically stable nanoparticle suspension to be stabilized solely by electrostatic repulsion, a zeta potential of $\pm 30 \mathrm{mV}$ is required as a minimum (Singare et al., 2010). The mutual repulsion of nanoparticles depends on having either a large negative or positive zeta potential. Zeta potential measurements of the nanoparticles are presented in Fig. 5. These show that Ag nanoparticles have a positive surface charge which increases with chitosan concentration from $+23.8 \mathrm{mV}$ at $1 \%(\mathrm{w} / \mathrm{v})$ to $+32.1 \mathrm{mV}$ at $3 \% \mathrm{w} / \mathrm{v}$ chitosan solution. Cu nanoparticles had a slightly higher positive surface charge which ranged from $+26.4 \mathrm{mV}$ at $1 \%(\mathrm{w} / \mathrm{v})$ to $+33.9 \mathrm{mV}$ at $3 \%(\mathrm{w} / \mathrm{v})$, although statistically the zeta potentials of $\mathrm{Ag}$ and $\mathrm{Cu}$ nanoparticles were not found to be significantly different to each other. The zeta potential of the nanoparticles increases with chitosan concentration due to the greater availability of protonized $\mathrm{NH}^{3+}$ on the surface of nanoparticles formed. This will produce a greater electrostatic repulsion between the particles and therefore a lower incidence of agglomeration and resulting in a more stable nanoparticle dispersion. 
Fig. $5 \mathrm{~b}$ shows zeta potentials of $\mathrm{Ag}, \mathrm{Cu}, \mathrm{Ag}+\mathrm{Cu}$ and $\mathrm{Ag} / \mathrm{Cu}$ nanoparticles prepared from $50 \mathrm{mM}$ metal salt solutions and $3 \%(\mathrm{w} / \mathrm{v})$ chitosan solutions respectively. In this instance the Ag nanoparticles have a slightly higher surface charge $(+37.8 \mathrm{mV})$ than Cu nanoparticles $(+35.5 \mathrm{mV})$. Mixed $(\mathrm{Ag}+\mathrm{Cu})$ nanoparticles gave a value of +39.1 $\mathrm{mV}$ and $\mathrm{Ag} / \mathrm{Cu}$ nanoparticles one of $+35.2 \mathrm{mV}$. These differences were not statistically significant.

As there may be an effect of particle size on the zeta potentials of the four nanoparticle types $(\mathrm{Ag}, \mathrm{Cu}, \mathrm{Ag}+\mathrm{Cu}$ and $\mathrm{Ag} / \mathrm{Cu})$, the zeta potentials were compared for selected samples which most closely corresponded to a mean particle size of $200 \mathrm{~nm}$. These were synthesized in $3 \%(\mathrm{w} / \mathrm{v})$ chitosan and corresponded to metal ion concentrations of $12.1,32.0$ and $18.2 \mathrm{mM}$ for $\mathrm{Ag}, \mathrm{Cu}$ and $\mathrm{Ag} / \mathrm{Cu}$ respectively. $\mathrm{Ag}+\mathrm{Cu}$ was made by mixing Ag prepared at $12.1 \mathrm{mM}$ with Cu prepared at $32.0 \mathrm{mM}$. The corresponding zeta potentials are $+33.8,33.1,32.6$ and $33.3 \mathrm{mV}$ for $\mathrm{Ag}, \mathrm{Cu}, \mathrm{Ag}+\mathrm{Cu}$ and $\mathrm{Ag} / \mathrm{Cu}$ respectively (Fig. $5 \mathrm{c}$ ). These are very similar to those shown in Fig. $5 \mathrm{~b}$ where all samples were prepared with a $50 \mathrm{mM}$ solution (corresponding to mean particle sizes of 793, 292, 542 and $633 \mathrm{~nm}$ respectively). This finding reveals that the concentration of metal salts used in the preparation does not significantly affect the charge of the nanoparticles. The results obtained here are consistent with those of Xiong et al. (2013), in which it was reported that the zeta potential of Cu nanoparticles is $+32 \mathrm{mV}$, suggesting that that value was high enough to maintain stable colloidal dispersions.

\subsection{Antimicrobial properties}

MIC and MBC tests were performed to assess the antibacterial activity of the nanoparticles towards $B$. subtilis and E. coli. The MIC is defined as the lowest concentration at which there is no visible growth whilst MBC is defined as the lowest concentration at which no colony is observed (Wei et al., 2009). MIC and MBC values towards $B$. subtilis and $E$. coli of $\mathrm{Ag}, \mathrm{Cu}, \mathrm{Ag} / \mathrm{Cu}$ and $\mathrm{Ag}+\mathrm{Cu}$ nanoparticles prepared from $50 \mathrm{mM}$ metal salt solutions are shown in Table 1. A lower MIC or MBC corresponds to higher antibacterial effectiveness. As a control, to assess the possible antimicrobial action of ascorbic acid, separate experiments were performed in which samples were prepared according to the method in Section 2.3.1, but in the absence of chitosan and silver or copper nitrate and tested against both E. coli and B. subtilis. 
These samples showed no bactericidal effect when undiluted, but an inhibitory effect at full strength and 1/2 dilution. However, under such conditions the ascorbic levels are typically a thousand times greater than those present in the nanoparticle suspensions detailed in Table 1, and therefore any antimicrobial effects directly due to the presence of ascorbic acid in our experiments can be neglected.

The results show that Ag nanoparticles have significantly higher MIC and MBC values for $B$. subtilis and $E$. coli than $C u$ nanoparticles at the same concentration of chitosan $(3 \% \mathrm{w} / \mathrm{v})$ and metal salts $(50 \mathrm{mM})$. The results presented here demonstrated that at the same metal salts concentration, Cu nanoparticles have a characteristically smaller particle size than Ag nanoparticles. Smaller particle size tends to enhance antibacterial properties because as size decreases, there are a larger number of atoms on the surface available to interact with bacteria (Marambio-Jones \& Hoek, 2010). A mixture of $\mathrm{Ag}$ and $\mathrm{Cu}$ nanoparticles at $50 \mathrm{mM}$ showed intermediate behaviour although statistically this was similar to that of Ag nanoparticles for both type of bacteria. The 50 $\mathrm{mM} \mathrm{Ag} / \mathrm{Cu}$ alloy nanoparticles showed the highest antibacterial effectiveness of all.

All the nanoparticles showed very similar values for MIC and MBC which shows that the nanoparticles have a bactericidal rather than bacteriostatic effect on these two bacteria.

Valodkar et al., 2011 reported MIC and MBC values of 0.26 and $0.78 \mathrm{mg} / \mathrm{L}$ for 10 $\mathrm{mM} \mathrm{Ag}$ nanoparticles and the MIC and MBC of 0.23 and $0.65 \mathrm{mg} / \mathrm{L}$ for $10 \mathrm{mM} \mathrm{Ag} / \mathrm{Cu}$ alloy nanoparticles against lower bacterial concentrations $\left(10^{4} \mathrm{CFU} / \mathrm{mL}\right)$ of $E$. coli than were employed here $\left(10^{8} \mathrm{CFU} / \mathrm{mL}\right)$. Taner et al., 2011 reported an MIC value only of $>150 \mathrm{mg} / \mathrm{L}$ for Ag nanoparticles and identical values for MIC and MBC of Ag?Cu nanoparticles of $0.5 \mathrm{mg} / \mathrm{L}$ against high concentrations $\left(10^{8} \mathrm{CFU} / \mathrm{mL}\right)$ of $E$. coli. The MIC/MBC values reported here are lower than those achieved by Valodkar et al., 2011 and Taner et al., 2011 which indicated better antibacterial activity and suggested that chitosan, which serves as stabilizing agent is also contributing to the antimicrobial effect. The findings obtained here are not directly comparable with those of Said-Galiev et al. (2011) as they did not report their findings in terms of MIC or MBC. Huang et al, (2004) synthesized nanoparticles using chitosan but did not report on the antimicrobial 
activity of their nanoparticles. The findings reported here reveal that MIC/MBC values of bimetallic alloy nanoparticles were substantially lower than that of pure i.e. single metal nanoparticles.

As particle size will have an effect on antimicrobial activity, due to differences in specific surface area, the samples are compared against each other in Table 2 keeping an approximately constant mean particle size across all samples of approximately 200 $\mathrm{nm}$ (as performed for the zeta potentials presented in Fig. 5c. On this basis the Ag nanoparticles showed significantly lower MIC and MBC values than Cu nanoparticles towards both types of bacteria. Thus it can be surmised that $\mathrm{Ag}$ has a greater intrinsic antimicrobial activity than $\mathrm{Cu}$. The lowest MIC and MBC values were observed for $\mathrm{Ag} / \mathrm{Cu}$ nanoparticles in contact with both $B$. subtilis and $E$. coli either at the same concentration of metal salts and chitosan or fixed nanoparticles size. Cu nanoparticles displayed statistically the same antimicrobial effect as was obtained with a mixture of $\mathrm{Ag}$ and Cu nanoparticles towards both B. subtilis and E. coli.

Bacteria bear a negative charge due to the excess number of carboxylic and other groups which make the cell surface negative (Stoimenov, Klinger, Marchin, \& Klabunde, 2002). The nanoparticle suspensions produced here have positive charge as revealed by zeta potential measurements. Electrostatic forces between positively charged nanoparticles and negatively charged bacteria cells will enhance the effect of antibacterial activity. Adhesion of nanoparticles to the surface of a bacterium alters its membrane properties ultimately causing death (Li et al., 2008). The MIC and MBC of the synthesized nanoparticles against both $B$. subtilis and $E$. coli revealed that the Gram-positive bacteria were more susceptible than the Gram-negative bacteria to the nanoparticles. This is most likely due to differences in bacterial cell-wall structure of Gram-positive and Gram-negative with the Gram-negative cell wall having a structure which is more complex than the Gram-positive cell wall.

\section{Conclusions}

$\mathrm{Ag}$ and $\mathrm{Cu}$ nanoparticles were synthesized using ascorbic acid as a reducing agent in chitosan solutions using an efficient microwave heating method. Moreover, the 
synthesis was fast, inexpensive, environmentally benign, energy efficient and does not produce toxic waste. It was shown that nanoparticle size could be controlled by manipulating the concentrations of chitosan and silver and copper nitrate used in their synthesis. Particle size could be increased either by decreasing the chitosan concentration or increasing the metal ion concentration. The nanoparticles produced had a positive surface charge and the chitosan used in their synthesis contributed to the stability of suspensions of such particles and prevented agglomeration. MIC and MBC testing showed a potent bactericidal effect with Ag nanoparticles showing a greater killing effect when compared to $\mathrm{Cu}$ nanoparticles at the same mean particle size. All the nanoparticles showed very similar values for MIC and MBC which shows that the nanoparticles have a bactericidal rather than bacteriostatic effect on these two bacteria. The greatest antimicrobial effect was seen when $\mathrm{Ag}$ and $\mathrm{Cu}$ are combined during synthesis to form alloyed particles. The use of the latter in medical applications is currently being investigated.

\section{Acknowledgements}

NMZ thanks the Ministry of Education, Malaysia, University Malaysia Pahang and Loughborough University for financial support. The authors would like to acknowledge Mr David Smith for technical assistance with experiments. 


\section{REFERENCES}

Ahmad, A., Mukherjee, P., Senapati, S., Mandal, D., Khan, M. I., Kumar, R., \& Sastry, M. (2003). Extracellular biosynthesis of silver nanoparticles using the fungus Fusarium oxysporum. Colloids and Surfaces B: Biointerfaces, 28, 313-318.

Cao, X. L., Cheng, C., Ma, Y. L., \& Zhao, C. S. (2010). Preparation of silver nanoparticles with antimicrobial activities and the researches of their biocompatibilities. Journal of Materials Science: Materials in Medicine, 21, 28612868.

Dai, J. H., \& Bruening, M. L. (2002). Catalytic nanoparticles formed by reduction of metal ions in multilayered polyelectrolyte films. Nano Letters, 2(5), 497-501.

Datta, K. K. R., Kulkarni, C., \& Eswaramoorthy, M. (2010). Aminoclay: A permselective matrix to stabilize copper nanoparticles. Chemical Communications (Cambridge, England), 46, 616-618.

Díaz-Visurraga, J., Daza, Pozo Valenzuela, C., Becerra, García Cancino, A., \& von Plessing, C. (2012). Study on antibacterial alginate-stabilized copper nanoparticles by FT-IR and 2D-IR correlation spectroscopy. International Journal of Nanomedicine, 7, 3597-3612.

El-Nour, K. M. M. A., Eftaiha, A., Al-Warthan, A., \& Ammar, R. A. A. (2010). Synthesis and applications of silver nanoparticles. Arabian Journal of Chemistry, 3, 135-140.

Esumi, K., Takei, N., \& Yoshimura, T. (2003). Antioxidant-potentiality of gold-chitosan nanocomposites. Colloids and Surfaces B: Biointerfaces, 32, 117-123.

Flemming, C. A., \& Trevors, J. T. (1989). Copper toxicity and chemistry in the environment: A review. Water, Air, and Soil Pollution. 44, 143-158.

Hsiao, M.-T., Chen, S.-F., Shieh, D.-B., \& Yeh, C.-S. (2006). One-pot synthesis of hollow $\mathrm{Au}_{3} \mathrm{Cu}_{1}$ spherical-like and biomineral botallackite $\mathrm{Cu}_{2}(\mathrm{OH})_{3} \mathrm{Cl}$ flowerlike 
architectures exhibiting antimicrobial activity. Journal of Physical Chemistry. B, 110, 205-210.

Huang, H., Yuan, Q., \& Yang, X. (2004). Preparation and characterization of metalchitosan nanocomposites. Colloids and Surfaces B: Biointerfaces, 39, 31-37.

Leung, T. C.-Y., Wong, C. K., \& Xie, Y. (2010). Green synthesis of silver nanoparticles using biopolymers, carboxymethylated-curdlan and fucoidan. Materials Chemistry and Physics, 121, 402-405.

Li, Q., Mahendra, S., Lyon, D. Y., Brunet, L., Liga, M. V, Li, D., \& Alvarez, P. J. J. (2008). Antimicrobial nanomaterials for water disinfection and microbial control: potential applications and implications. Water Research, 42, 4591-602.

Li, T, Albee, B., Alemayehu, M., Diaz, R., Ingham, L., Kamal, S., Rodriguez, M., \& Bishnoi, S.W. (2010). Comparative toxicity study of Ag, Au, and Ag-Au bimetallic nanoparticles on Daphnia magna. Analytical and Bioanalytical Chemistry, 398, 689700.

Lim, S., \& Hudson, S. M. (2004). Application of a fiber-reactive chitosan derivative to cotton fabric as an antimicrobial textile finish. Carbohydrate Polymers, 56, 227234.

Mallick, K., Witcomb, M. J., \& Scurrell, M. S. (2006). In situ synthesis of copper nanoparticles and poly(o-toluidine): A metal-polymer composite material. European Polymer Journal, 42, 670-675.

Marambio-Jones, C., \& Hoek, E. M. V. (2010). A review of the antibacterial effects of silver nanomaterials and potential implications for human health and the environment. Journal of Nanoparticle Research, 12, 1531-1551.

Muzzarelli, R.A.A., Tanfani, F., \& Emanuelli, M. (1984). Chelating derivatives of chitosan obtained by reaction with ascorbic acid. Carbohydrate Polymers, 4, 137-151. 
Muzzarelli, R.A.A. (1985). Removal of uranium from solutions and brines by a derivative of ascorbic acid and chitosan. Carbohydrate Polymers, 5, 85-89 (1985).

Muzzarelli, R.A.A. (2010). Chitins and chitosans as immunoadjuvants and nonallergenic drug carriers. Marine Drugs, 8, 292-312.

Muzzarelli, R.A.A. (2011) Potential of chitin/chitosan-bearing materials for uranium recovery: An interdisciplinary review. Carbohydrate Polymers, 84, 54-63.

No, H. K., Park, N.Y., Lee, S.H., \& Meyers, S. P. (2002). Antibacterial activity of chitosans and chitosan oligomers with different molecular weights. International Journal of Food Microbiology, 74, 65-72.

Perera, S., Bhushan, B., Bandara, R., Rajapakse, G., Rajapakse, S., \& Bandara, C. (2013). Morphological, antimicrobial, durability, and physical properties of untreated and treated textiles using silver-nanoparticles. Colloids and Surfaces $A$ : Physicochemical and Engineering Aspects, 436, 975-989.

Ribeiro, S., Hussain, N., \& Florence, A. T. (2005). Release of DNA from dendriplexes encapsulated in PLGA nanoparticles. International Journal of Pharmaceutics, 298, 354-360.

Said-Galiev, E. E., Gamzazade, a. I., Grigor'ev, T. E., Khokhlov, a. R., Bakuleva, N. P., Lyutova, I. G., Shtykova, E. V., Dembo, K. A. \& Volkov, V. V. (2011). Synthesis of $\mathrm{Ag}$ and $\mathrm{Cu}$-chitosan metal-polymer nanocomposites in supercritical carbon dioxide medium and study of their structure and antimicrobial activity. Nanotechnologies in Russia, 6, 341-352.

Sanpui, P., Murugadoss, A., Prasad, P. V. D., Ghosh, S. S., \& Chattopadhyay, A. (2008). The antibacterial properties of a novel chitosan-Ag-nanoparticle composite. International Journal of Food Microbiology, 124, 142-146. 
Sharma, V. K., Yngard, R. A., \& Lin, Y. (2009). Silver nanoparticles: Green synthesis and their antimicrobial activities. Advances in Colloid and Interface Science, 145, 83-96.

Singare, D. S., Marella, S., Gowthamrajan, K., Kulkarni, G. T., Vooturi, R., \& Rao, P. S. (2010). Optimization of formulation and process variable of nanosuspension: An industrial perspective. International Journal of Pharmaceutics, 402, 213-220.

Solanki, J. N., Sengupta, R., \& Murthy, Z. V. P. (2010). Synthesis of copper sulphide and copper nanoparticles with microemulsion method. Solid State Sciences, 12, 1560-1566.

Stoimenov, P. K., Klinger, R. L., Marchin, G. L., \& Klabunde, K. J. (2002). Metal oxide nanoparticles as bactericidal agents. Langmuir, 18, 6679-6686.

Sundaresan, K., Sivakumar, A., Vigneswaran, C., \& Ramachandran, T., . (2012). Influence of nano titanium dioxide finish, prepared by sol-gel technique, on the ultraviolet protection, antimicrobial, and self-cleaning characteristics of cotton fabrics. Journal of Industrial Textiles, 41, 259-277.

Taner, M., Sayar, N., Yulug, I. G., \& Suzer, S. (2011). Synthesis, characterization and antibacterial investigation of silver-copper nanoalloys. Journal of Materials Chemistry, 21, 13150-13154

Thakkar, K. N., Mhatre, S. S., \& Parikh, R. Y. (2010). Biological synthesis of metallic nanoparticles. Nanomedicine: Nanotechnology, Biology, and Medicine, 6, 257-262.

Tolaymat, T. M., El Badawy, A. M., Genaidy, A., Scheckel, K. G., Luxton, T. P., \& Suidan, M. (2010). An evidence-based environmental perspective of manufactured silver nanoparticle in syntheses and applications: A systematic review and critical appraisal of peer-reviewed scientific papers. Science of the Total Environment, 408, 999-1006. 
461 Twu, Y.-K., Chen, Y.-W., \& Shih, C.-M. (2008). Preparation of silver nanoparticles using chitosan suspensions. Powder Technology, 185, 251-257.

463

464

465

466

467

468

469

470

471

472

Valodkar, M., Modi, S., Pal, A., \& Thakore, S. (2011). Synthesis and anti-bacterial activity of $\mathrm{Cu}, \mathrm{Ag}$ and $\mathrm{Cu}-\mathrm{Ag}$ alloy nanoparticles: A green approach. Materials Research Bulletin, 46, 384-389.

Wei, D., Sun, W., Qian, W., Ye, Y., \& Ma, X. (2009). The synthesis of chitosan-based silver nanoparticles and their antibacterial activity. Carbohydrate Research, 344, 2375-2382.

Xiong, J., Wu, X., \& Xue, Q. (2013). Biomolecule-assisted synthesis of highly stable dispersions of water-soluble copper nanoparticles. Journal of Colloid and Interface Science, 1, 41-46. 


\section{LIST OF FIGURES}

Figure 1. Nanoparticle suspensions of (a) Ag and (b) Cu synthesized in $10 \mathrm{mM}$ metal salts and different concentration of chitosan of 1,2 and $3 \%(w / v)$, respectively, (from left to right) (c) From left to right: $\mathrm{Ag}, \mathrm{Cu}, \mathrm{Ag}+\mathrm{Cu}$ and $\mathrm{Ag} / \mathrm{Cu}$ nanoparticles suspensions synthesized in $50 \mathrm{mM}$ metal salts and $3 \%(\mathrm{w} / \mathrm{v})$ of chitosan.

Figure 2 Absorbance spectra of the nanoparticles of (a) $\mathrm{Ag}$ and (b) Cu synthesized in 10 $\mathrm{mM}$ metal salts and different concentrations of chitosan of 1,2 and $3 \%(\mathrm{w} / \mathrm{v})$, respectively, (c) $\mathrm{Ag}, \mathrm{Cu}, \mathrm{Ag}+\mathrm{Cu}$ and $\mathrm{Ag} / \mathrm{Cu}$ in $50 \mathrm{mM}$ metal salts and $3 \%$ (w/v) of chitosan respectively.

Figure 3. Mean particle size of (a) Ag (b) Cu nanoparticles synthesized in $10 \mathrm{mM}$ metal salts and different concentrations of chitosan. Error bars represent standard deviations from the mean in triplicate experiments. Different letters indicate differences significant at $p \leq 0.05$.

Figure 4. Mean particle size of nanoparticles prepared by different concentrations of (a) silver nitrate (b) copper nitrate (c) silver and copper nitrate (combined concentration) at $3 \%(\mathrm{w} / \mathrm{v})$ of chitosan. Error bars represent standard deviations from the mean of triplicate experiments. Different letters indicate differences significant at $p \leq 0.05$.

Figure 5. Zeta potential of the nanoparticles of (a) Ag and $\mathrm{Cu}$ of $10 \mathrm{mM}$ metal salts and different concentration of chitosan (b) $\mathrm{Ag}, \mathrm{Cu}, \mathrm{Ag}+\mathrm{Cu}$ and $\mathrm{Ag} / \mathrm{Cu}$ of $50 \mathrm{mM}$ metal salts and 3\% (w/v) of chitosan (c) $\mathrm{Ag}, \mathrm{Cu}, \mathrm{Ag}+\mathrm{Cu}$ and $\mathrm{Ag} / \mathrm{Cu}$ of with nitrate concentrations adjusted to give $200 \mathrm{~nm}$ mean particle size (with 3\% w/v chitosan). Error bars represent standard deviation from the mean of triplicate experiments. Different letters indicate differences significant at $p \leq 0.05$. 
499 Table 1: MIC and MBC values of $\mathrm{Ag}, \mathrm{Cu}, \mathrm{Ag} / \mathrm{Cu}$ and $\mathrm{Ag}+\mathrm{Cu}$ nanoparticles synthesized 500 in $50 \mathrm{mM}$ metal salts and $3 \%(\mathrm{w} / \mathrm{v})$ of chitosan towards $B$. subtilis and E. coli. Identical 501 subscripted letters denote no statistically significant differences $(p>0.05)$ between MIC 502 and MBC in column-based comparisons and identical superscripted letters denote no 503 statistically significant differences $(p>0.05)$ in row-based comparisons as indicated by 504 one way ANOVA with Bonferroni multiple comparison tests.

505 Table 2: MIC and MBC values of $\mathrm{Ag}, \mathrm{Cu}, \mathrm{Ag} / \mathrm{Cu}$ and $\mathrm{Ag}+\mathrm{Cu}$ nanoparticles of $200 \mathrm{~nm}$ 506 mean particle size towards $B$. subtilis and $E$. coli. Identical subscripted letters denote no 507 statistically significant differences $(p>0.05)$ between MIC and MBC in column-based 508 comparisons and identical superscripted letters denote no statistically significant 509 differences $(p>0.05)$ in row-based comparisons as indicated by one way ANOVA with 510 Bonferroni multiple comparison tests. 


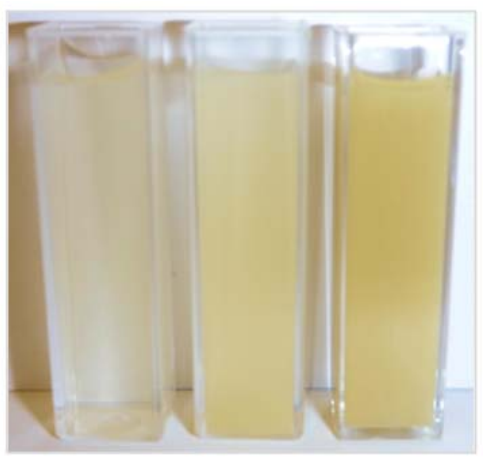

(a)

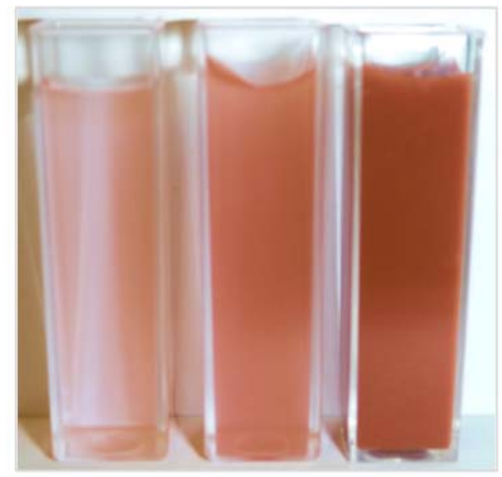

(b)

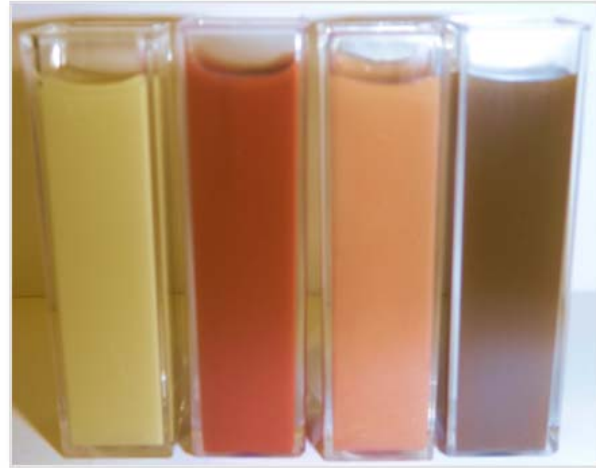

(c)

Fig. 1. 

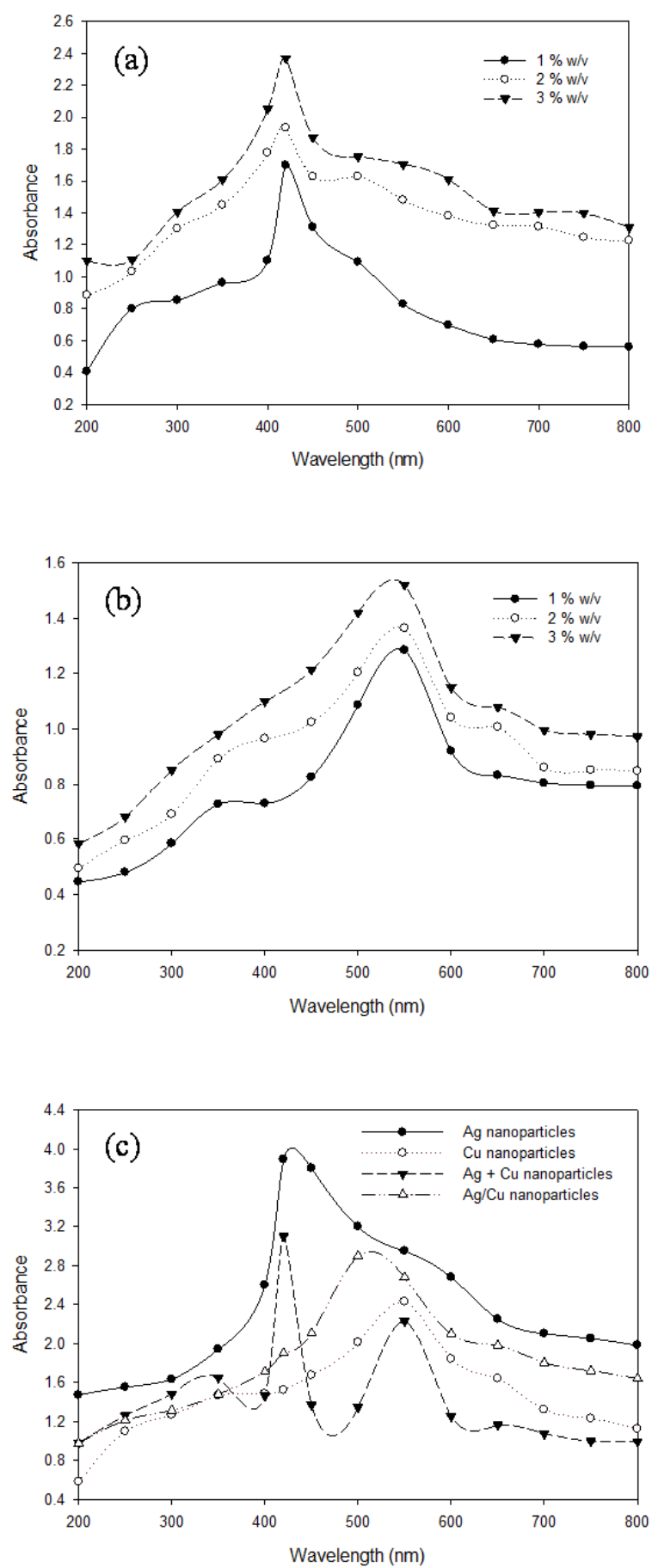

Fig. 2. 


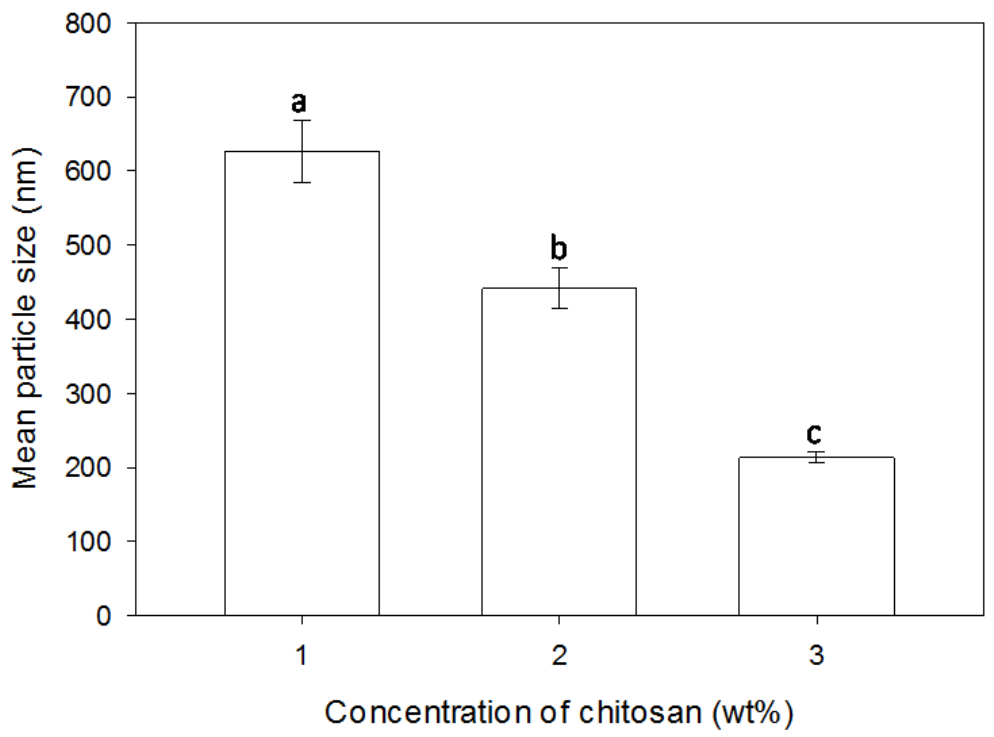

(a)

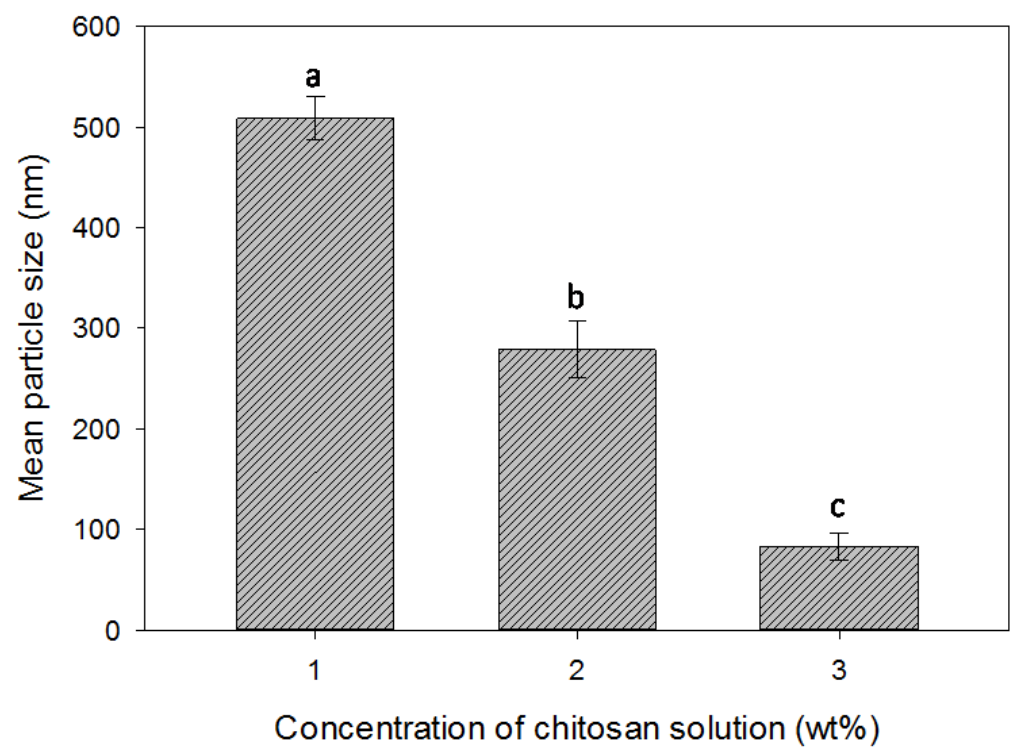

(b)

Fig. 3. 

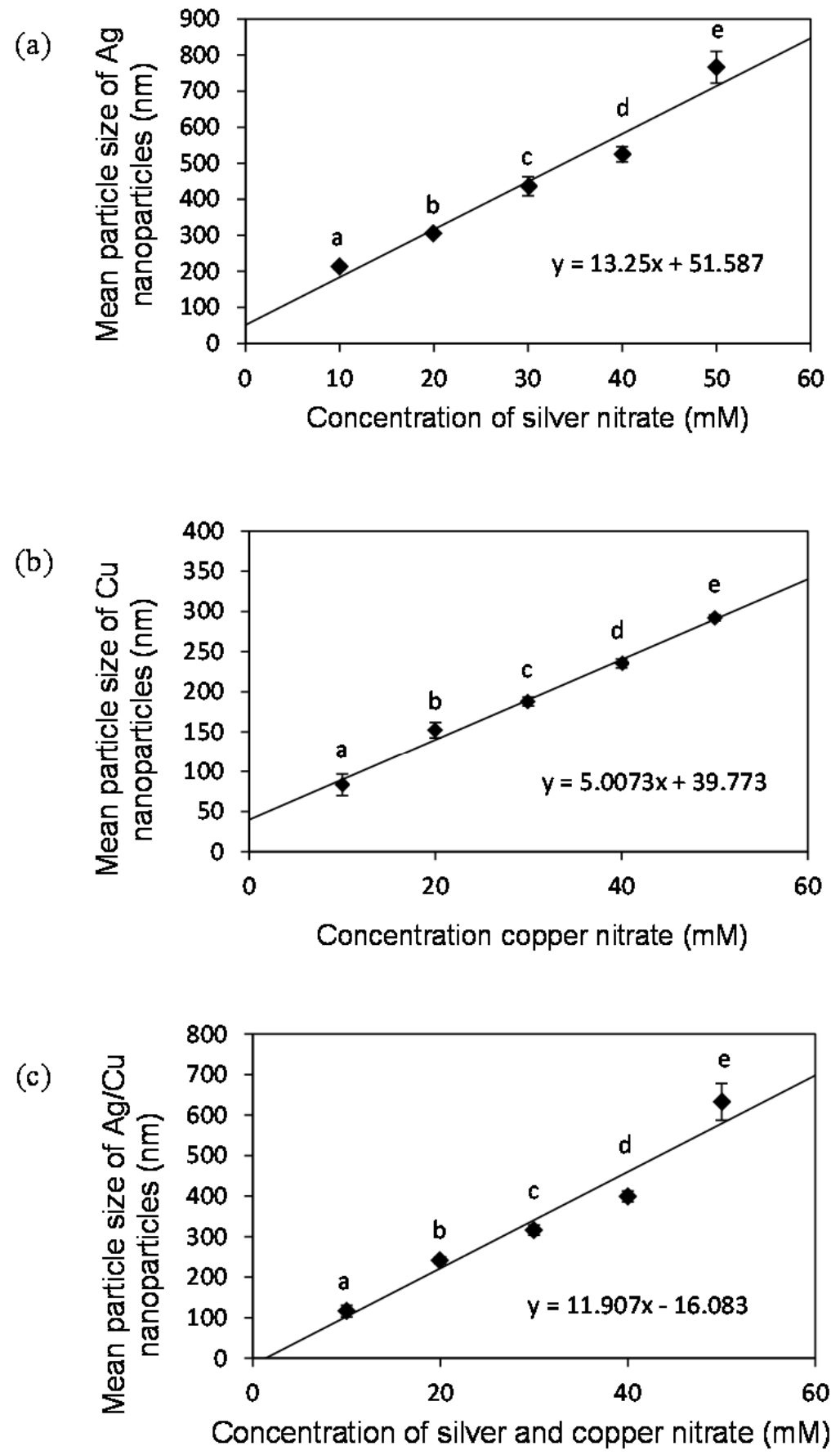

Fig. 4. 
(a)

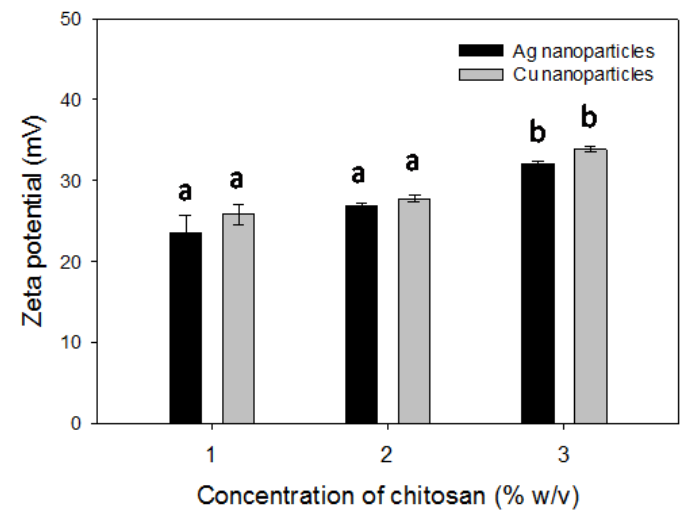

(b)

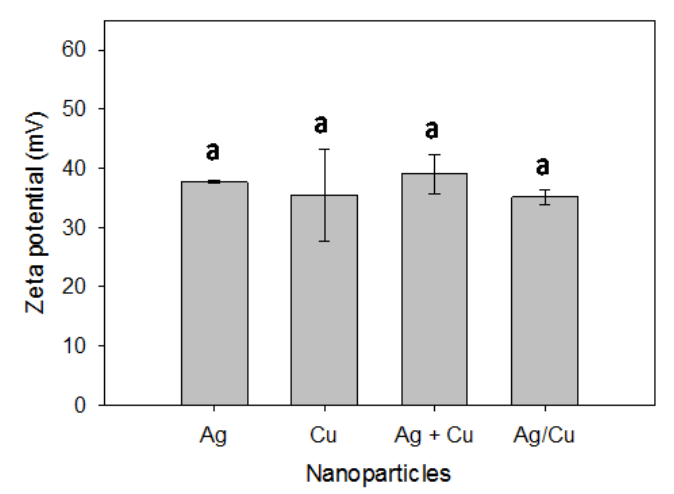

(c)

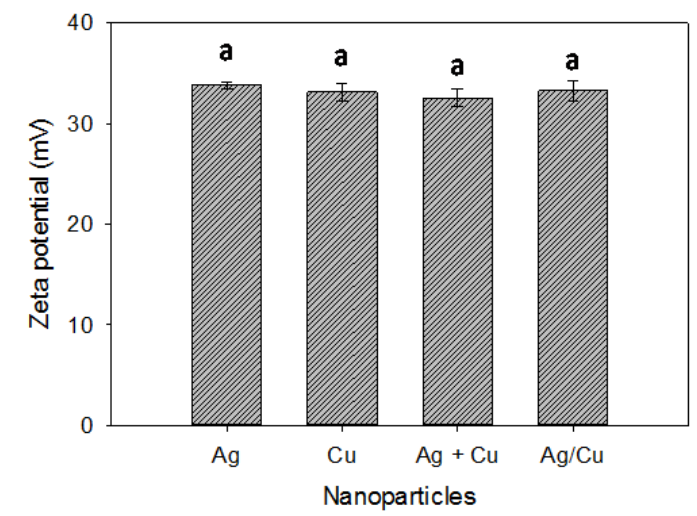

Fig. 5. 
Table 1:

\begin{tabular}{|c|c|c|c|c|c|c|c|c|}
\hline \multirow[t]{2}{*}{ Bacteria } & \multicolumn{3}{|c|}{$\mathrm{MIC}(\mathrm{mg} / \mathrm{L})$} & \multicolumn{5}{|c|}{$\begin{array}{c}\mathrm{MBC} \\
(\mathrm{mg} / \mathrm{L})\end{array}$} \\
\hline & $\mathrm{Ag}$ & $\mathrm{Cu}$ & $\mathrm{Ag}+\mathrm{Cu}$ & $\mathrm{Ag} / \mathrm{Cu}$ & $\mathrm{Ag}$ & $\mathrm{Cu}$ & $\mathrm{Ag}+\mathrm{Cu}$ & $\mathrm{Ag} / \mathrm{Cu}$ \\
\hline B. subtilis & $0.652^{\mathrm{A}}$ & $0.313^{\mathrm{B}}$ & $0.576_{a}^{A}$ & $0.179^{\mathrm{C}}$ & $0.666_{a}^{A}$ & $0.438^{\mathrm{B}}$ & $0.596{ }_{a}^{A}$ & $0.194^{\mathrm{C}}$ \\
\hline E.coli & $0.793_{\mathrm{a}}^{\mathrm{A}}$ & $0.469_{b}^{B}$ & $0.670_{b}^{A}$ & $0.273_{b}^{C}$ & $0.746_{a}^{A}$ & $0.531_{b}^{B}$ & $0.700_{b}^{A}$ & $0.298_{b}^{C}$ \\
\hline
\end{tabular}

Table 2:

\begin{tabular}{lllllllll}
\hline Bacteria & \multicolumn{3}{c}{ MIC (mg/L) } \\
& \multicolumn{3}{c}{$\mathrm{MBC}$} \\
& $\mathrm{Ag}$ & $\mathrm{Cu}$ & $\mathrm{Ag}+\mathrm{Cu}$ & $\mathrm{Ag} / \mathrm{Cu}$ & $\mathrm{Ag}$ & $\mathrm{Cu}$ & $\mathrm{Ag}+\mathrm{Cu}$ & $\mathrm{Ag} / \mathrm{Cu}$ \\
\hline B. subtilis & $0.172_{\mathrm{a}}^{\mathrm{A}}$ & $0.320_{\mathrm{a}}^{\mathrm{B}}$ & $0.262_{\mathrm{a}}^{\mathrm{B}}$ & $0.054_{\mathrm{a}}^{\mathrm{C}}$ & $0.189_{\mathrm{a}}^{\mathrm{A}}$ & $0.387_{\mathrm{a}}^{\mathrm{B}}$ & $0.336_{\mathrm{a}}^{\mathrm{B}}$ & $0.061_{\mathrm{a}}^{\mathrm{C}}$ \\
\hline E.coli & $0.199_{\mathrm{a}}^{\mathrm{A}}$ & $0.433_{\mathrm{b}}^{\mathrm{B}}$ & $0.327_{\mathrm{b}}^{\mathrm{B}}$ & $0.076_{\mathrm{b}}^{\mathrm{C}}$ & $0.199_{\mathrm{a}}^{\mathrm{A}}$ & $0.470_{\mathrm{b}}^{\mathrm{B}}$ & $0.379_{\mathrm{b}}^{\mathrm{B}}$ & $0.081_{\mathrm{b}}^{\mathrm{C}}$ \\
\hline
\end{tabular}

